\title{
TREATMENT PATTERNS OF ARAB PATIENTS WITH
}

RHEUMATOID ARTHRITIS

\author{
S. Zahirovic ${ }^{1}$, S. Dargham¹, S. Al Emadi², H. Badsha ${ }^{3}$, H. Halabi ${ }^{4}$, M. Hammoudeh², B. Masri ${ }^{5}$, I. Uthman $^{6}$, \\ Z. Mahfoud ${ }^{1}$, H. Ashour ${ }^{2}$, M. Kapiri ${ }^{1}$, and T. Arayssi ${ }^{1 .}$
}

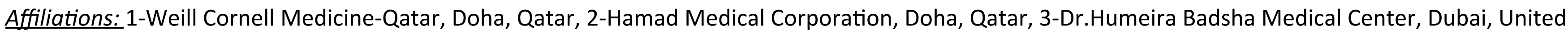
Arab Emirates, 4-King Faisal Specialist Hospital and Research Center, Jeddah, Saudi Arabia, 5-Jordan Hospital, Amman, Jordan, 6-American University of Beirut, Beirut, Lebanon

\section{INTRODUCTION}

* There is limited information on the treatment patterns of rheumatoid arthritis (RA) across the Arab region.

\section{OBJECTIVE}

* To describe the treatment patterns of patients of Arab ancestry with RA living in five Middle Eastern countries

\section{METHODS}

* This is a secondary data analysis of a cross-sectional study of RA patients enrolled in the Genetics of Rheumatoid Arthritis in Some Arab States multicenter case-control study.

* Data were collected between October 2012 and March 2016 from consecutive RA patients attending rheumatology outpatient clinics in the Kingdom of Saudi Arabia (KSA), Jordan, Lebanon, Qatar and the United Arab Emirates (UAE).

* Eligibility criteria :

* Patients had to be $>18$ years of age,

* Patients had to be of Arab ancestry by self-report,

* Patients had to have RA diagnosed according to the 1987

American College of Rheumatology (ACR)

* Comparison of medication patterns between the five country sites were conducted using the Chi-square and Fisher's exact tests.

\section{FIGURE 1. Medication patterns of Arab RA patients}

Biologics DMARDs Methotrexate Steroids

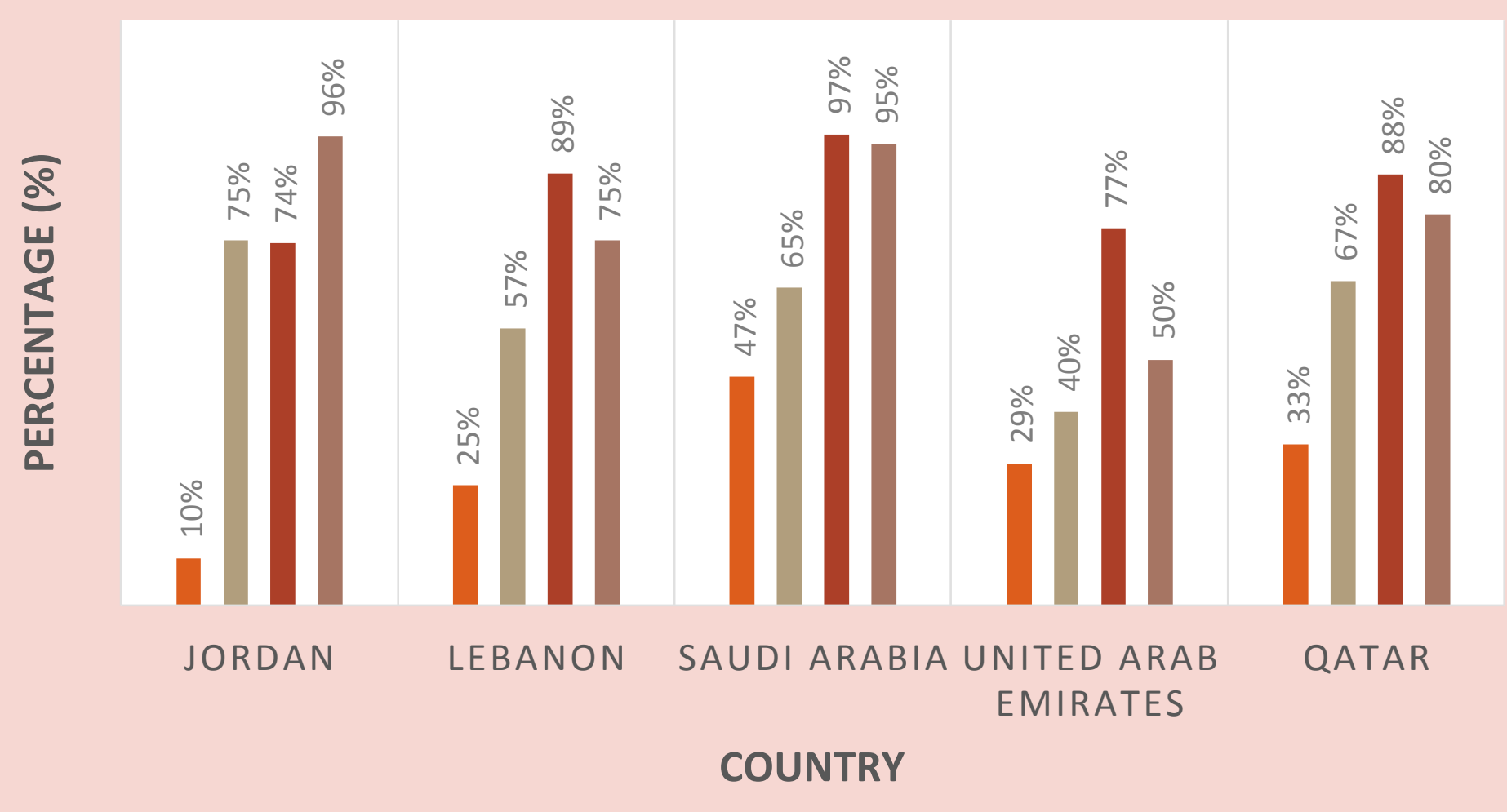

\section{CONCLUSION}

* Disparities in usage of methotrexate, biologics and steroids were noted across the five countries.

* National GDP, as well as some other unique features in each country likely affected these.

* Developing treatment guidelines specific to this region could contribute in delivering standardized therapy to RA patients.

\section{FUNDING}

* This study was made possible by NPRP grant 4-344-3-105 from the Qatar National Research Fund (a member of Qatar Foundation). The statements made herein are solely the responsibility of the author[s].

\section{RESULTS}

* A total of 895 patients with RA were enrolled from the five participating sites.

* The baseline characteristics are summarized in Table 1.

* Methotrexate $(87.8 \%)$ and steroids $(80.6 \%)$ were the most commonly ever-used medications across all sites.

* Only one third of patients ever-used TNF-inhibitor biologics.

* Highest utilization of steroids was identified in Jordan and KSA ( $p$-value $<0.001$ )

* Highest ever-use of TNF-inhibitor biologics was reported in KSA ( $p$-value < 0.001).

TABLE 1. Baseline Characteristics

\begin{tabular}{|c|c|c|}
\hline & \\
\hline & $\mathbf{N}$ & $\%$ \\
\hline \multicolumn{3}{|l|}{ Gender } \\
\hline Male & 135 & 15.1 \\
\hline Female & 760 & 84.9 \\
\hline \multicolumn{3}{|l|}{ Marital Status } \\
\hline Single & 112 & 12.5 \\
\hline Ever-married & 783 & 87.5 \\
\hline \multicolumn{3}{|l|}{ Education } \\
\hline No formal education/Primary & 245 & 27.4 \\
\hline Middle/Secondary School & 341 & 38.1 \\
\hline University & 309 & 34.5 \\
\hline \multicolumn{3}{|l|}{ Cigarette Smoking Status } \\
\hline Never Smoked & 717 & 80.1 \\
\hline Ever Smoked & 178 & 19.9 \\
\hline \multicolumn{3}{|l|}{ Shisha Smoking Status } \\
\hline Never Smoked & 795 & 88.8 \\
\hline Ever Smoked & 100 & 11.2 \\
\hline \multicolumn{3}{|l|}{ Self-Reported Ancestry } \\
\hline Gulf & 373 & 41.7 \\
\hline Levant & 347 & 38.8 \\
\hline Africa & 140 & 15.6 \\
\hline Other & 35 & 3.9 \\
\hline \multicolumn{3}{|l|}{ Nationality } \\
\hline Expats & 285 & 31.8 \\
\hline Nationals & 610 & 68.2 \\
\hline \multicolumn{3}{|l|}{ Coronary Artery Disease } \\
\hline No & 861 & 96.3 \\
\hline Yes & 33 & 3.7 \\
\hline \multicolumn{3}{|l|}{ History of Stroke/TIA } \\
\hline No & 880 & 98.4 \\
\hline Yes & 14 & 1.6 \\
\hline \multicolumn{3}{|l|}{ Peripheral Vascular Disease } \\
\hline No & 874 & 97.8 \\
\hline Yes & 20 & 2.2 \\
\hline \multicolumn{3}{|l|}{ Diabetes Mellitus - Type II } \\
\hline No & 775 & 86.7 \\
\hline Yes & 119 & 13.3 \\
\hline
\end{tabular}

